\section{Arquitecturas en la Villa de Monleón: Análisis de los Procesos de Repoblación a partir de la Estratigrafía Muraria}

Miguel Ángel Muñoz García

(Arqueólogo, Especialista en Restauración Arquitectónica)

\section{Resumen}

La Villa de Monleón fue objeto de excavaciones arqueológicas en el año 1996 con el fin de completar los estudios cara a la restauración de sus murallas. De estas y del estudio estratigráfico murario se derivaron dos fases anteriores a la repoblación de Alfonso IX (1217).

Palabras clave: UEM, cuerpo de fábrica, mampostería, mos quadratum y sillares apiconados.

\begin{abstract}
The Villa de Monleón was the object of archaeological excavations in 1996 with the aim of completing studies during the restoration of its walls. From this and from the stratigraphic wall study, two phases prior to the repopulation of Alfonso IX (1927) were found.
\end{abstract}

Key words: Stratigraphic Wall Unit (SWU), body of stonework, stone walls, mos quadratum, sculpted stonework.
La Villa de Monleón, sita en la provincia de Salamanca, se encuentra a unos 47 kilómetros de la capital; se asienta sobre un otero a $878 \mathrm{~m}$. sobre el nivel del mar; domina la confluencia del Río Alagón, con el arroyo Riofrío y el Navalmandiles. Dibuja un pintoresco paisaje en el cual, muralla, castillo y campanario se integran armónicamente con el medio natural circundante. Entre los días 5 al 23 de Agosto de 1996, dirigimos una campaña de excavaciones arqueológicas con el fin de contribuir al proyecto de restauración de sus murallas que, hasta la fecha, no se ha materializado (Muñoz García, Serrano Piedecasas, 1997). Tras dividir los lienzos en cuerpos de fábricas se practicaron sondeos en la Puerta del Sol y en los tramos norte. Se planteó un estudio global, en el cual la estratigrafía de los sondeos, debía integrarse en la resultante de las lecturas de paramentos de los tramos de muralla investigados; además de los análisis murarios practicados en la iglesia parroquial y castillo señorial. De todas las operaciones se desprendieron las siguientes fases de ocupación y constructivas:

—Fase I: Localizada en las UE 107 Y 108, anteriores a la construcción de la muralla.

-Fase II: Fundación de la muralla. fonso IX

-Fase III: «Repoblación» oficial del rey leonés Al-

-Fase IV: Corresponde al s. XV, en el cual se reforma el Castillo Señorial. También se distinguen obras en la Iglesia Parroquial.

-Fase IV: Únicamente se reforma el Templo en el XVIII.

-Fase V: Corresponde a la época contemporánea y abarca tanto el deterioro de los monumentos, como la reciente restauración que sufrió el Castillo.

\section{A. EL SOTOSUELO DE LA MURALLA: LA FASE I}

Uno de los interrogantes abiertos por la excavación son las diferencias de cimentación, halladas en los sondeos practicados en los cuerpos de fábrica norte (C.F. IV y V). La unidad de excavación 2 no halló cimiento alguno en la estructura de muralla. No obstante descubrió que la misma apoyaba directamente sobre un depósito artificial de cascotes (UE. 107 y 108), mientras la unidad de excavación 3 presentaba una cimentación de mampostería con mortero de cal (UEM 57) en el cuerpo de fábrica IV. ¿Que significa esta diferencia, teniendo en cuenta que los dos cuerpos de fábrica, como veremos, tenían un mismo origen? En primer lugar, descartaremos que la razón del depósito de bloques sea la necesidad de aterrazar el terreno para buscar una base de apoyo firme; hubiera sido más lógico haber utilizado la técnica de mampuesto aparejado con mortero, que es más sólida y estable. La poliorcética plenomedieval en muchas ocasiones no excavaba o aterrazaba el subsuelo para levantar una cer- 


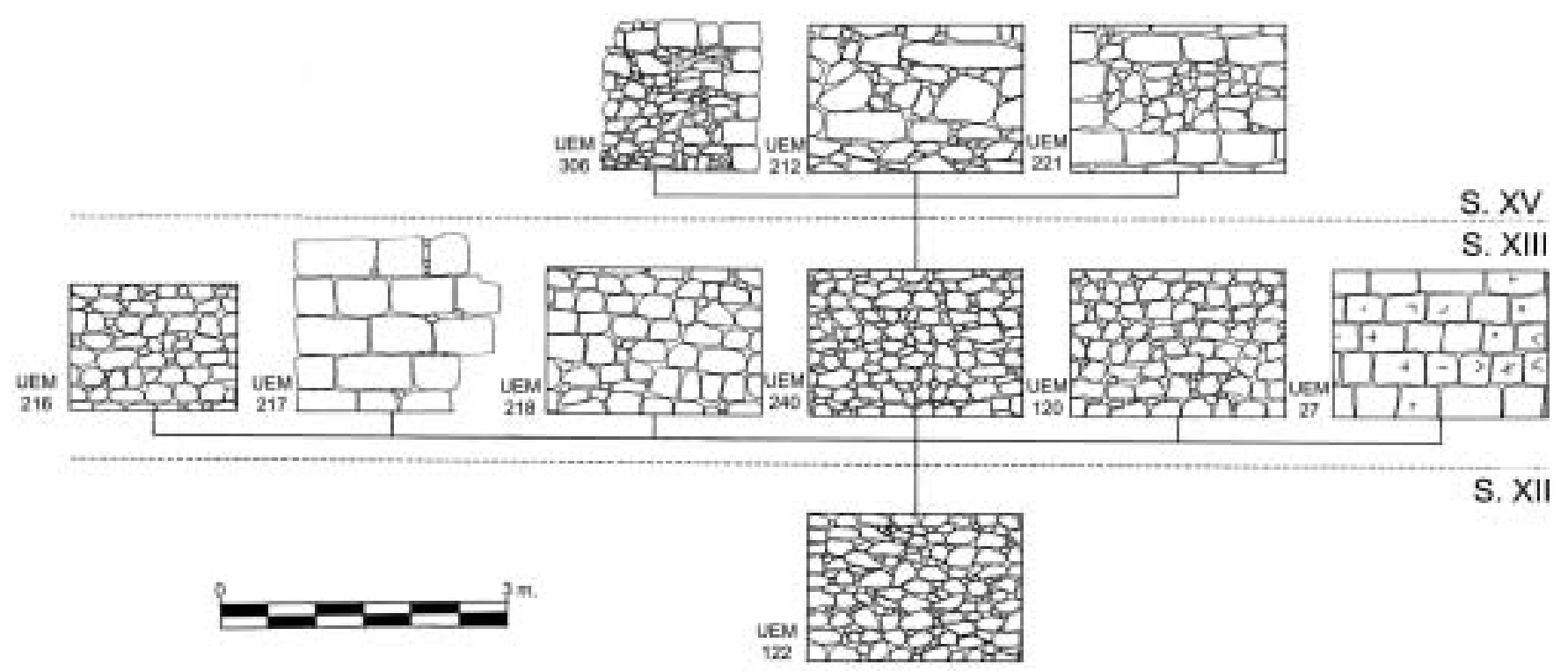

Fig. 1. Matriz de Fábricas Murarias de los principales edificios de Monleón. UEM 122, 27, 120 y 240 pertenecen a la muralla y sus puertas. La UEM $217,216,221$ y 212 se localizan en el castillo, mientras que la UEM 306 se individualizó en la iglesia parroquial

ca. Generalmente, el muro defensivo se asienta sobre la roca madre u otro tipo de suelo natural. Las excepciones las encontramos en la existencia de fosos, sin descartar tampoco desniveles puntuales, que soluciona la UEM 57 y 70 como asiento del cuerpo de fábrica IV.

Las dos "cimentaciones" no son coetáneas en el tiempo. Cuando se decidió la erección de la cerca en mampostería, seguramente el depósito de cascotes (UE 107 y 108) se encontraba in situ. Quizá la celeridad que imponen las circunstancias, impidió retirar cascotes allí depositados. En todo caso se limitarían a allanar superficialmente del amontonamiento de bloques de pizarra y cornubianita.

Ahora bien, más difícil es responder la siguiente cuestión. Sí el deposito de cascotes, no es obra de los alarifes de la muralla, ¿a quien corresponde su autoría y contexto? La solución deberá esperar futuros trabajos arqueológicos, pues carecemos de elementos sólidos que construyan un argumento definitivo.

Los bloques presentaban un aspecto anárquico, en el cual, fue imposible distinguir estructura alguna. Es decir, el estado en que se encontraría un derrumbe que parece prolongarse en el subsuelo de los cuerpos de fábrica norte de la muralla. Es posible que estemos ante la ruina de una primitiva muralla de piedra en seco. Existe un verraco prerromano en el pueblo de Monleón; sin embargo la excavación no descubrió material alguno de la II. ${ }^{a}$ Edad del Hierro. De momento nos inclinamos por creer que la supuesta defensa, pertenecería a un asentamiento altomedieval. Posiblemente, el mismo contexto de yacimientos como el Castillo Viejo de Valero o Peña del Rey, que también dispusieron de fortificaciones de piedra en seco.

\section{B. FASE II: LA FUNDACIÓN DE LA MURALLA}

La datación de esta fase se basa ya en la propia lectura estratigráfica muraria. El análisis revela un fase constructiva de fundación. El momento constructivo presente se realiza en mampostería (U.E.M. 122). Además en el cuerpo de fábrica $\mathrm{V}$, se distingue al exterior una zarpa sobre la que apoya toda la estructura de la muralla (UEM 111), también con técnica de mampuesto concertado. A esta fase también atribuimos el mencionado cimiento UEM 57 y 70.

Gutiérrez González opina que esta técnica no se generaliza hasta la plena edad media —al menos en las fortificaciones conservadas-, aunque se conociera y utilizara anteriormente en obras civiles y religiosas. En 1160 se emplea este mismo aparejo en la construcción de las murallas de Castrotorafe (GuTiérRez GonZÁlez, 1995). Pero no será el modo de construir, el factor que por si sólo nos advierta de su datación; contrastémoslo con los datos históricos existentes. Que Monleón ya existía en el 1099, lo confirma la Carta de Arras de Dña. Berenguela. En el Tratado de Tordehumos de 1194 quedó vetado cualquier tipo de nueva fundación entre la frontera de los reinos de Castilla y León. Ello nos retrotrae la construcción de la muralla por lo menos antes de esta fecha. Una de las puertas es llamada "de Coria»; hecho que da fé de la importancia que tuvo la comunicación con la actual ciudad extremeña en la fundación y desarrollo histórico de nuestra villa. 
En cuanto a Coria, sabemos que hubo una efímera ocupación por parte de Alfonso VI en el 1076; el monarca tuvo que resignarse a perderla, a raíz del freno almorávide, que suponen las derrotas de las Sagrajas (1085) y Ucles (1108). Su sucesor Alfonso VII el Emperador, aprovecha el ocaso de la presión africana para impulsar de nuevo la reconquista. De esta manera irrumpe en la actual Extremadura y en el 1142 vuelve a conquistar la plaza de Coria. Los primeros años del reinado del monarca leonés Fernando II, siguen con esta tónica. Las guerras fronterizas con el reino de Castilla, junto a la virulenta irrupción almohade, obligan a aparcar los intentos de expansión; los musulmanes africanos recuperan Alcántara, y en el 1174 consiguen poner sitio a Ciudad Rodrigo sin conseguirlo. Al garantizar el paso del valle del Alagón, hacia la antigua ciudad hispano-musulmana, Monleón adquiere una posición estratégica nada despreciable. De esta manera, se convertía en vía alternativa a la de Ciudad Rodrigo, — camino habitual por el que confluían casi todas las expediciones que partían desde el oeste del Reino de León hacia Al-Andalus-, además de reforzar las comunicaciones con la propia Coria. Así pues establecemos, una fecha post-quem para la fundación de nuestra villa, que debió ser posterior a la conquista definitiva de Coria del año 1142 .

La erección de una muralla en una villa fronteriza del XII, es muy difícil desgajarla de un proceso repoblador o «infeudadon», al ser obra que requiere de organización y concurso de especialistas dirigidos por un poder sólido. La forma de construir de doble paramento y núcleo, implica un cierta planificación previa, y una primera división del trabajo.

Podemos distinguir entre los que extraían la piedra y los que la aparejaban. El material empleado es la roca cornubianita, que no requiere una explotación de canteras en toda regla, pues aflora esparcida por el mismo campo; ello nos lleva a suponer que, para obtener la materia prima no fue necesario importar mano de obra abundante, pues los mismo repobladores podían cumplir este cometido. Por otro lado, el empleo de la población local para la construcción de una cerca, era una práctica común en la Edad Media. En la documentación correspondiente se recoge, cómo en la fundación de Ciudad Real de 1255, «Alfonso X mandó a los del lugar como ficiesen la cerca» (VALDEÓN BARUQUe, 1991).

Caso diferente es el de los asignados a elevar el muro, pues representa faena que necesita de más pericia y maestría. Sin duda, esta parte debía estar a cargo de alarifes o canteros, ya sea una cuadrilla completa o el mínimo necesario para la dirección de las obras. Pensemos que la construcción de la muralla se tuvo que sancionar con el conoci- miento de cálculos y mediciones, que no estaba al alcance de cualquier campesino. Tampoco la composición de los morteros, era arte que este último dominaba, pues sus viviendas se construían con diferente oficio y material. El alarife por lo menos debió ser docto en la elaboración de dos mezclas de cal diferentes: una más arenosa en el ripio interior, y otra con más yeso para el paramento. Respecto al corte de la piedra, el careo y las aristas, solamente denotan uso de cincel romo, escoda y, acaso, el puntero. Desconocemos si dominaron oficios más finos pues, en este momento constructivo, no se ha conservado ningún elemento que requiera instrumentos más sutiles.

Urbanísticamente, la muralla del s. XII fijó básicamente la extensión de la Villa Medieval y Moderna, pues la expansión hacia el norte de caserío data del s. XX. La existencia de mamposterías semejantes en el los lienzos contiguos a la Puerta de Coria ratifican esta afirmación.

La fundación de Monleón sucedida en algún momento comprendido entre el 1142 y el 1194 , no puede encuadrarse en ninguna de las repoblaciones reales, dado que nada semejante se menciona en ninguna de las grandes crónicas. La pregunta de quiénes fueron sus promotores, es interrogante que como tantas veces en arqueología no tiene respuesta definitiva. Sin embargo, nuevamente el examen de las noticias históricas arroja luz a la cuestión.

Conocida es la reacción de los caballeros del concejo salmantino, al saber que Fernando II promueve la repoblación de Ciudad Rodrigo. Alzados en abierta rebeldía, deben ser sometidos por la hueste real en el año 1162. La historiografía ha explicado esta actitud, por la preocupación del concejo salmantino de restar territorio a su alfoz. Sin embargo, algunos historiadores a menudo olvidan que los concejos de realengo del Duero no solamente vivían de las cabañas ganaderas y la agricultura. La guerra no sólo era un mandato real o una necesidad defensiva, sino también una actividad lucrativa más. La apertura del Camino de Santiago, poco a poco va forjando un pequeño comercio de productos de lujo, que no solamente tiene mercado en la alta nobleza feudal, sino también en los caballeros villanos que vivían en estos concejos. Sus habitantes difícilmente hubieran podido costearlos si no fuera por las ganancias que proporciona el saqueo y pillaje de tierras islámicas (MARTín, 1985). De hecho, expediciones que únicamente tienen este fin aparecen codificadas en la Partidas de Alfonso X (SOLER, 1995).

Los caballeros salmantinos debieron ver amenazada una de sus actividades más lucrativas al establecerse el concejo de Ciudad de Rodrigo, pues ya no podrían pasar tan cómodamente por la ruta más transitada hacia la Extremadura. El paso por la antigua Vía de la Plata estaba guarda- 

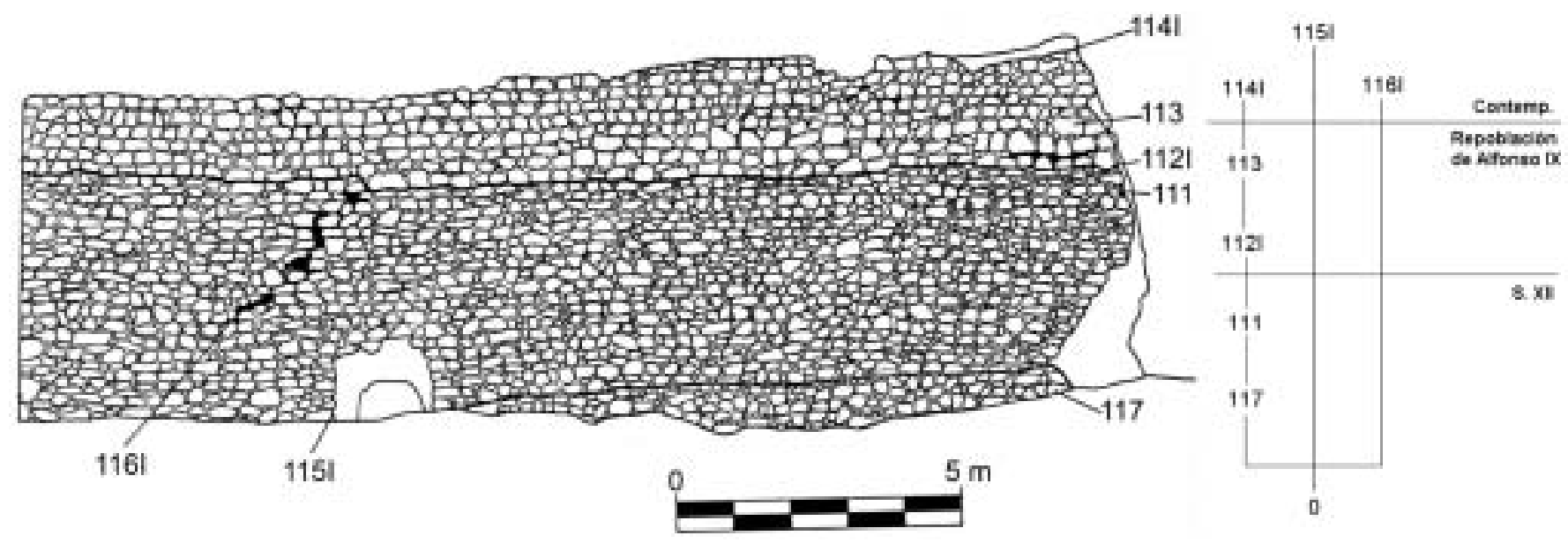

Fig. 2. Análisis estratigráfico del cuerpo de fábrica $\mathrm{V}$

do por Bejar, que había jurado fidelidad a Alfonso VIII de Castilla, mientras en Portugal consolidaba su soberanía Alfonso Enriques. Ello significaba que las algaras de los caballeros del concejo salmantino, en el mejor de los casos, podrían ser observadas por los repobladores de Ciudad Rodrigo. Así pues, ¿se iban a resignar a que sus pretensiones de botín se vieran frenadas por estos últimos? Ante la imposición real, resulta razonable pensar que buscasen una vía alternativa hacia tierras islámicas. Por estos años, debía existir ya un antiguo camino, a través de la actual comarca extremeña de las Hurdes, que comunicaba directamente con Coria. Éste seguramente se consolidó al levantarse la muralla de Monleón, que nosotros hemos identificado en la fase II.

Hay suficientes razones históricas, como para sospechar cierta sombra del concejo salmantino en esta primera «repoblación» de Monleón. No obstante esta influencia, débil o fuerte, no resultó duradera a corto plazo, pues en 1217 Alfonso IX repobló Monleón como villa independiente. De ello tratará nuestro siguiente apartado.

\section{FASE III: LA REPOBLACIÓN DE ALFONSO IX}

Las relaciones entre el sucesor de Fernando II y Alfonso VIII de Castilla no fueron precisamente cordiales. A la subida al trono de Alfonso IX se reanuda la guerra civil, aprovechando el castellano la debilidad que presentaba la silla del trono leonesa. El Tratado de Tordehumos que prohíbe la repoblación de la Sierra no contribuye a mitigar la rivalidad. Prueba de ello, es que el monarca leonés se abstuvo de luchar en las dos grandes batallas que alienaron a Alfonso VIII, contra el imperio almohade -Alarcos (1195) y Las Navas de Tolosa (1212)—. Precisamente, la derrota de Alarcos retrotrae los impulsos de los castellanos, y en consecuencia, toca el turno de revancha al rey de León: ataca la frontera caste- llano-leonesa de nuevo, y también aprovecha la coyuntura para iniciar las repoblaciones serranas y transerranas de Miranda del Castañar, Salvatierra, Salvaleón y, como no, Monleón (GonZÁlez, 1943). Los cronistas de Alfonso IX coinciden en destacar de su reinado la toma definitiva de casi toda la Extremadura, al caer Cáceres en 1229. En base a esto, podemos suponer que las vías de acceso hacia el sur estuvieron muy concurridas a principios del XIII. Nuestro monarca debió sentir especial predilección por la ruta que comunicaba Salamanca con Coria por Monleón, pues no contento con la repoblación de la presente villa, también hace lo propio con Miranda del Castañar. Con ello aseguraba aún más la vía que bajaba por Sotoserrano y el Valle del Alagón. Aquí no sólo se contempla el tránsito de huestes hacia Extremadura, pues la rivalidad castellano-leonesa es factor a tener muy en cuenta: las cuñas de Alfonso VIII - los concejos de Béjar y Plasencia- amenazaban las posesiones del Reino de León en el sur.

Julio González reseña la fecha de 1217 (GONZÁLEZ, 1943) para la repoblación alfonsina de nuestra villa. A este respecto Ángel Barrios, seguramente condicionado por la «Carta de Arras» de Dña. Berenguela, es más flexible con la fecha y la sitúa a partir de 1199 (BARRIOS, 1997). Sea como fuere es ahora cuando se la dota de sus instituciones concejiles, y presenta todos los elementos que identifican a una comunidad de villa y tierra. En el ámbito arquitectónico, esto se traduce en muralla, castillo e iglesia. En el caso del templo no se identifican elementos del s. XIII; sin embargo no es el caso de la cerca y el castillo. Respecto a las técnicas empleadas ahora se utiliza el mos-quadratum y los sillares apiconados, siendo el granito la principal materia prima

La vieja muralla de mampostería necesitaba de reparaciones. $\mathrm{Al}$ interior del cuerpo de fábrica $\mathrm{V}$ se ha identifica- 


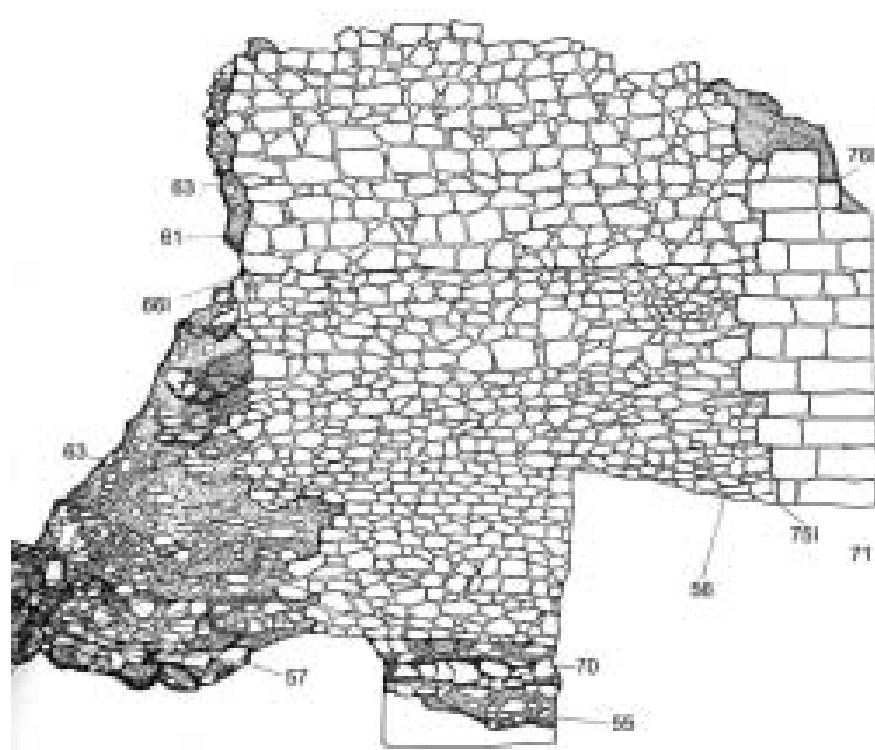

Fig. 3. Análisis estratigráfico del cuerpo de fábrica IV

do una interfaz (UEM 121) que dibuja una diagonal en pendiente sobre el paramento. Esta forma no admite dudas: su relleno con sus sillares apiconados de granito (UEM 120 ), se realiza como consecuencia de una destrucción previa, que nada tiene que ver con las obras del XIII. Un simple fallo de cimiento habría arrastrado a las hileras bajas de la fase anterior; tampoco creemos que en momentos anteriores se hubiera dejado inacabada dejando dicha diagonal. Descartadas estas hipótesis, la única posibilidad que se nos antoja menos problemática, es la de que es consecuencia de un conflicto armado, en el cual se procediera a desmantelar las estructura de la muralla. En 1196 Alfonso VIII de Castilla y Pedro II de Aragón son los protagonistas de una expedición sobre el territorio leonés que ataca los castillo de Ardón, Castrogonzalo, Castrotierra, Alba de Aliste y Monrreal (GONZÁLEZ, 1943). Este ultimo se sitúa a escasos kilómetros, en el actual término municipal de Casafranca. Es muy posible que esta expedición también alcanzara Monleón. No sólo por ser una plaza enemiga más sino, obviamente, por constituir también una amenaza directa sobre las fundación castellana de Béjar.

Además de esta reparación, también se eleva metro y medio la estructura de toda la muralla. El uso del granito es ya prueba directa de la apertura de canteras. Es posible que fueran las hoy abandonadas en el actual Monte el Alcaide, dentro del propio término municipal.

Con mos quadratum se ejecuta la Puerta de la Villa y la parte inferior del la Puerta del Sol (UEM 27), las jambas y arcos de las puertas (UEM 25, 45, 46 y 44), también en

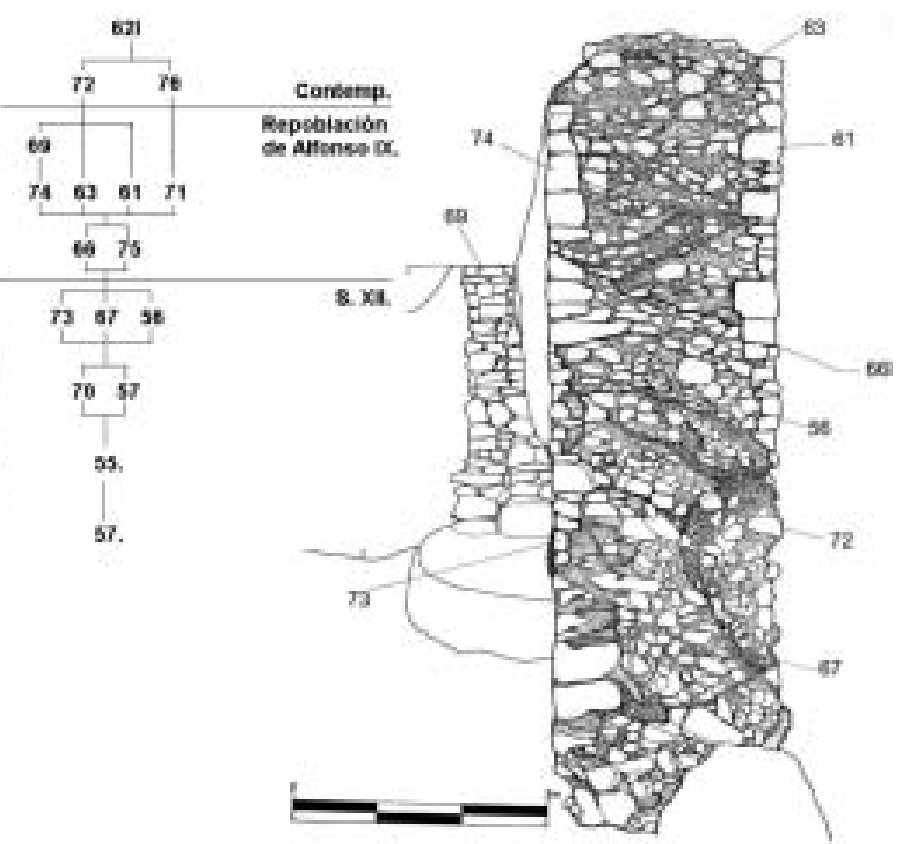

el acceso del Sol), y el remate de las esquinas (UEM. 41 en la Puerta del Sol, UEM 71 en cuerpo de fábrica IV, y UEM. 217 de la torre del homenaje del castillo). Sus sillares se realizaron con maza, puntero, cincel, delimitándose forma y dimensiones, con plomada, escuadra y corredera. Dada la dureza del material, la gradina debió desecharse, por lo que el acabado de la pieza, seguramente se completó con cincel de boca estrecha. Es posible que con este último instrumento, se realizasen también las marcas de cantero. Apuntemos algunas medidas de los sillares que conserva: 75 40,5530 y $35 \quad 60 \mathrm{~cm}$.

Los sillares apiconados (UEM 120), presentes tanto en la Puerta del Sol, como en los Cuerpos de fábrica analizados de la muralla, se pudieron haber tallado en escoda, aunque nuevamente la dureza granítica aconsejan el uso de maza y puntero.

También hemos comprobado el uso de mamposterías que difieren de la etapa anterior. Ahora se hacen más cuidadas, no se utiliza excesiva ripia, y en consecuencia la junta de mortero presenta un aspecto más limpio. El uso de la mampostería contemporáneamente al mos quadratum y los sillares apiconados, puede interpretarse desde el ahorro de medios que supone para el cantero la utilización de material reaprovechado. Sin embargo la explicación no basta, pues todas las fábricas están perfectamente individualizadas con un propósito determinado.

Se percibe cierta voluntad estética al combinar las texturas cromáticas marrón y gris, que respectivamente presenta abajo la cornubianita y arriba el granito. Alguien 
podría alegarnos, que tal disposición es motivo de la casualidad histórica; la sencilla consecuencia de utilizarse primero un tipo de piedra y luego otro. Sin embargo, la intencionalidad del efecto bicromático es manifiesta en los análisis estratigráficos realizados. Tanto el interior de la Puerta del Sol como la escalera de acceso en el interior cuerpo de fábrica IV presentan esa fábrica diferenciada, y ambas pertenecen a este mismo momento constructivo. Esto último invalidaría cualquier intento de explicar casualmente este bicromatismo, que produce el granito y la piedra cornubianita sobre la muralla. El maestro cantero de esta fase, tuvo en mente el presente efecto y posiblemente así lo planificó desde un primer momento. Es irrelevante que se consiguiera con nuevas estructuras, o aprovechando la vieja cerca del XII.

Por otro lado, la combinación de diferentes texturas de material es algo habitual en toda la arquitectura pleno y bajomedieval. Desde luego, el caso de la Península Ibérica no llegó a las cotas musivarias de los edificios medievales bizantinos o italianos, realizados en mármol de diferentes colores, pero ello no quiere decir que el cantero o alarife peninsular desechase posibilidades creativas a su alcance. De hecho la combinación de materiales de diferentes texturas, era práctica conocida en Al-Andalus desde época altomedieval. La excavación sistemática del yacimiento de Alarcos ha puesto de manifiesto, que la muralla está construida por dos técnicas claramente diferenciadas. La cerca construida en 1191 por orden de Alfonso VIII, está integrada por un zócalo monumental en aparejo ciclópeo y llagueado adornado de ripia con piedra volcánica y material cerámico, mientras que en altura se soluciona en tapiales (ZoZAYA, 1995).

Es innegable que todas estas construcciones están condicionadas por circunstancias como las tecnológicas y el uso de materiales cercanos, sin embargo, resulta difícil de creer que el efecto visual resultante no fuera buscado exprofeso por los maestros que estaban a cargo de las obras. También las hileras en piedra de diferente composición, que animan la torre del homenaje de castillo y el interior de la Puerta de la Villa, deben ponerse en relación con el efecto bicromático aquí descrito.

Ahora bien, la forma en que el granito remata la vieja cerca de mampostería, hace sospechar que la diferencia de texturas no responda solamente a pretensiones estéticas. La arquitectura militar era también la manifestación material de posesión. Ya dijimos anteriormente que una de las acciones en la creación de un concejo de realengo era la erección de la muralla; además de ser símbolo que distingue la villa del exterior, lo es también del poder real que la repuebla. En el caso de Monleón, al no ser hábitat de nueva creación, es posible que Alfonso IX - $\mathrm{o}$ en su defecto sus delegados-, sintieran la necesidad de reafirmar su autoridad "COronando» con granito la cerca del XII; de esta manera, se exteriorizaba materialmente la posesión de la plaza por parte del monarca leonés.

Con parecido argumento debemos explicar la ausencia de accesos y torres correspondientes a la centuria anterior. La puerta y el cubo o torre sobrellevan buena parte de la carga emblemática, que supone una cerca en la mentalidad medieval. La ruptura entre interior y exterior que supone la muralla, hace especial protagonista a la torre, puesto que acentúa la verticalidad de los muros, además permite una visión que se pierde en la lejanía; una especie de dominio mediante la vista (LE GOFF, 1989). La puerta es el lugar donde mejor se expresan las relaciones intra y extramuros, pues es el lugar por donde pasan todos los que vienen del exterior; no hay lugar más idóneo para que el poder revele su presencia y propiedad.

Sí no basta con que las unidades murarias estratigráficas de granito avisen al caminante que se aproxima a una villa regia, la autoridad se puede remarcar con el impuesto del portazgo. Y naturalmente, este debe ser cobrado en un marco que sea portavoz del prestigio que rodea a quien lo cobra. De todo esto debieron ser muy conscientes los nuevos repobladores; de ahí que las puertas sean todas rehechas y no conservemos ninguna entrada de etapas anteriores. En consecuencia, tres son las entradas de hacia 1200 y las tres de diferente tipología. Obviamente, lo dicho hasta ahora no contradice las disposiciones puramente poliorcéticas que deben acompañar el diseño de las mismas. No olvidemos que siempre la entrada de un punto fortificado estará en el punto de mira del atacante, pues es de perogrullo remarcar que su conquista le puede garantizar la toma de la villa.

La Puerta de la Villa pertenece a la tipología de puerta-torre, muy difundida en este momento histórico. Se construye en mos quadratum excepto la cara superior intramuros. Presenta marcas de cantero y acceso en forma de arco apuntado, siendo la única que tenía rastro. Su excepción se justifica si pensamos que las otras dos puertas tienen elementos flanqueantes que las resguardan. El diseño de la Puerta del Sol protege su flanco derecho, mientras que la de Coria se encuentra bajo la protección lateral de la torre de homenaje del castillo. Es posible que el maestro cantero la juzgase vulnerable, al sobresalir más de la muralla, y en consecuencia decidiera reforzar la seguridad con el rastro.

En cuanto a la Puerta de Coria, poco podemos decir puesto que sillares de jambas y arco se encuentran hoy saqueados. Su tipo responde a la de puerta protegida por un sólo elemento turriforme, que en este caso corresponde al 


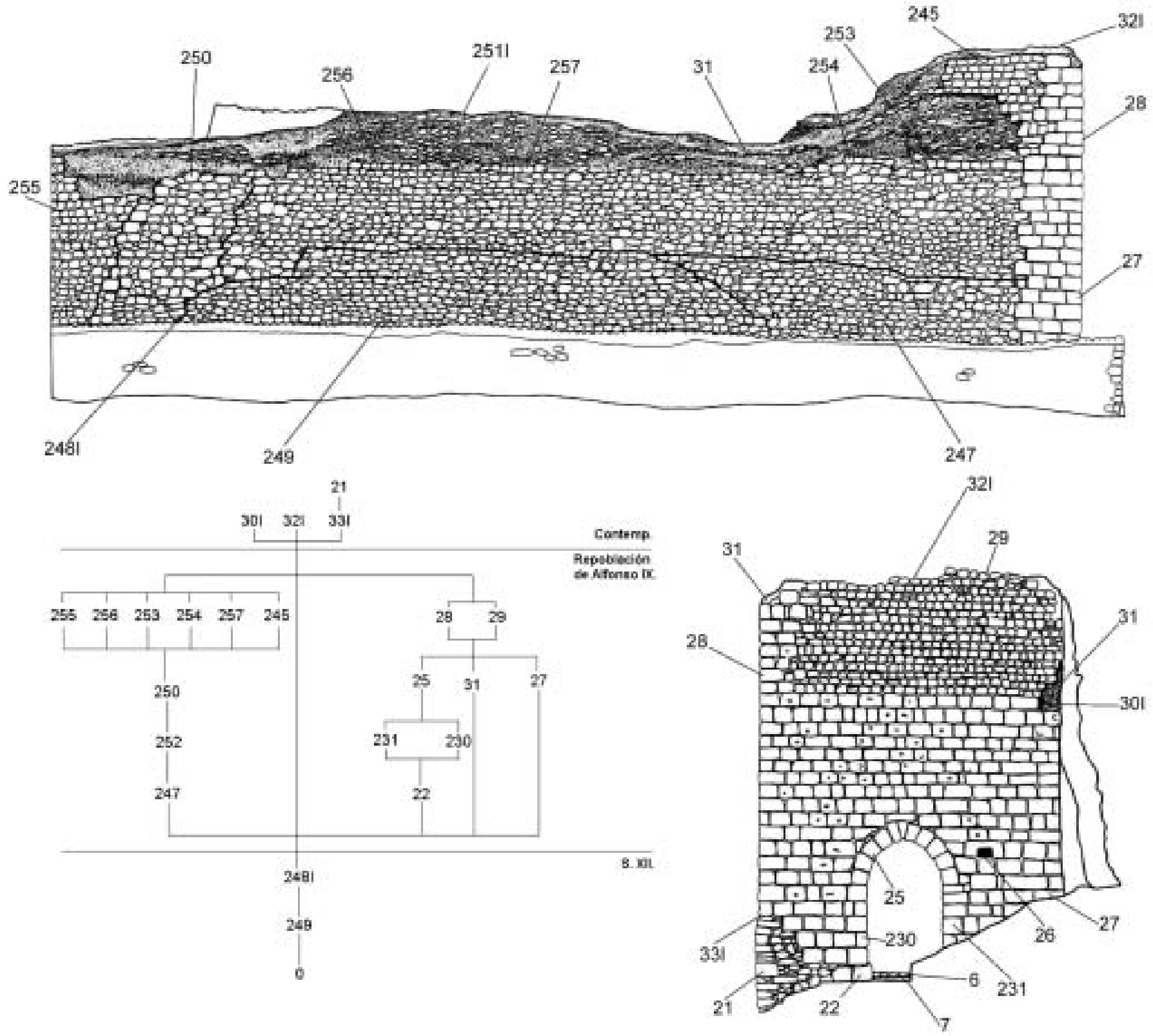

Fig. 4. Análisis estratigráfico de los paramentos exteriores de la Puerta del Sol

castillo de Monleón. La lectura estratigráfica del paramento sur de la Torre del Homenaje revela que su origen también se encuentra en la acción repobladora de Alfonso IX. Se ha identificado una almena cegada sobre la misma que pertenecería al s. XIII (UEM 214). Cabe preguntarse si en este momento el castillo de Monleón se limitaba a una simple torre cuadrangular integrada en la muralla.

De la tipología en acodo de la Puerta del Sol, hemos hablado arriba y en el capítulo correspondiente; retomamos nuestro discurso de los modos constructivos, puesto que la misma contiene datos que nos permiten extraer información histórica trascendente. En la Puerta del Sol, la combi- nación mos quadratum inferior y los sillares apiconados superiores, rematados con sillería en las esquinas, es modo de construir no exclusivo de Monleón. El mismo esquema se repite en la Torre de los Templarios de Idanha Vella, en Portugal. De idéntica cronología, apoya sobre un plinto de un antiguo templo romano; eleva un primer cuerpo de sillería y también remata en sillares apiconados con otros escuadrados en las esquinas.

Creemos más razonable, que el parecido puede deberse a la difusión de un modo de construcción que sería adoptado por diferentes maestros. También es menester tener presente, que no siempre era posible reproducir este 
tipo. Por lo menos, las piezas apiconadas requieren de piedra especial como el granito, que no se encuentra en todas partes.

Así pues, podemos concluir que la obra de esta muralla, fue producto de un maestro que estaba al tanto de las últimas modas constructivas y de las últimas innovaciones poliorcéticas. Ello es muy indicativo, del interés que $\mathrm{Al}$ fonso IX puso en la repoblación de Monleón. Sin embargo, por mucho que nos sorprendan todos los matices que la muralla encierra, no debemos catalogarla de excepcional. La expansión urbana de los s. XII y XIII favoreció el intercambio de tecnología al ser más fácil la circulación de bienes y personas. En este ambiente, el arte canteril encontró un excelente "mercado», que afectó tanto a la construcción de fortificaciones como a las nuevas canteras que abren las catedrales góticas.

\section{FASE IV Y V: MONLEÓN BAJO MEDIEVAL Y MODERNO}

La repoblación del XIII no se tradujo en una autonomía duradera. La villa fué donada al concejo salmantino en 1249, por deseo de Fernando III. A partir de entonces, la historia bajomedieval de Monleón, estará unida a los caprichos de las oligarquías que gobiernan Salamanca. Señalamos que las principales transformaciones de su arquitectura, se sucederán en el castillo de la segunda mitad del XV, sin olvidarnos del Templo Parroquial, cuyas reformas llegan hasta época moderna. El castillo es expresión de los intentos de señorialización que sufre Monleón, al intentarla desgajar del alfoz salmantino. Esta fortaleza responde a los preceptos bajomedievales de la poliorcética señorial.

La reforma de la Torre de Homenaje, presenta gran contraste en sus técnicas de ejecución. Es probable que el granito proceda del mismo lugar que abasteció las obras del XIII. El modo de escuadrar el material da fe de la maestría de los canteros que intervinieron. Algunos sillares tienen más de un metro, lo cual obligaría a disponer de un sistema especial de elevación. Dado que las obras se realizan sobre otra torre más antigua, seguramente la elevación de las piezas se solucionó con grúas. Las garitas (EA 201 y 226) son sobresalientes obras de estereotomía; cronológicamente nada extrañas pues el arte canteril alcanzará sus mayores cotas desde fines del la centuria de 1400 . También la talla aparece entrelazada con piezas irregulares de cornubianita (UEM 221), sin embargo las unidades murarias más inferiores de la fase IV presentan una groserísima mampostería, en la cual, se entremezcla abundante material reprovechado (UEM 212). El contraste debemos atribuirlo a la celeridad con que Rodrigo Maldonado debe construir el Castillo. Sobre la iglesia, las técnicas canteriles de sillería se usaron menos brillantemente. En la centuria de 1400, hemos identificado que éstas se emplearon para el refuerzo de esquinas y en la espadaña. El resto fue solucionado en mampostería de irregulares piezas de tamaño menor.

\section{Bibliografía}

A.A.V.V., 1995, Alarcos Medieval: La Batalla de Alarcos, en ZoZAYA, (coord.) Alarcos, el Fiel de la Balanza, Toledo.

Barrios García A., 1997, El Poblamiento Medieval Salmantino, en Mínguez (coord.), Historia de Salamanca II, Edad Media, Salamanca.

Brogiolo G. P., 1988, Archeología dell'Edilizia Storica, Como.

GONZÁLEZ J., 1943, Repoblación de la Extremadura Leonesa, Hispania 14.

GuTIERrEZ GonZÁlez J.A, 1995, Fortificaciones y Feudalismo en el Origen del Reino Leones (s. IX-XIII), Valladolid.

Le Goff J., 1991, Construcción y Destrucción de la Ciudad Amurallada, en de De Seta, Le Goff, La Ciudad y sus Murallas, Madrid.

Martín J. L, 1985, La Afirmación de los Reinos (s. I-XIII), Historia de Castilla y León, Ámbito.

Muñoz García M.A., Serrano Piedecasas L.M., 1997, I. a Campaña de Excavaciones Arqueológicas y Lectura de Paramentos en la Villa de Monleón, Informe inédito depositado en la Consejería de Educación y Cultura de la Junta de Castilla y León.

Soler DE CAMPO, 1995, Guerra y Armamento hacia 1200 d.C., en ZoZAYA (coord.), Alarcos, el Fiel de la Balanza, Toledo.

VALDEÓn BARUQUE J., 1991, Reflexiones sobre las Murallas Urbanas de la Castilla Medieval, en DE SeTA, Le Goff, La Ciudad y sus Murallas, Madrid. 